\title{
sciendo
}

\section{The accounting practitioner as a driver of digitalization pace}

\author{
Oana Cristina STOICA \\ Bucharest University of Economic Studies, Bucharest, Romania \\ stoicaoana14@stud.ase.ro \\ Liliana IONESCU-FELEAGĂ \\ Bucharest University of Economic Studies, Bucharest, Romania \\ liliana.feleaga@cig.ase.ro
}

\begin{abstract}
Accounting digitalization is a very important topic nowadays, not only for practitioners, but also for scholars and many different institutions. Digitalization influences the accounting profession through many ways, but the rhythm of digitalization firstly depends on people involved. Having that the accounting practitioner is the main actor in this field, it is very important to know how his behavior drives the pace of digitalization and whether his experience increases or reduces its rhythm. Using a case-based experiment with $2 \times 2$ between subjects and full factorial design, this paper examines the influence of the accountants' experience and their behavior on digitalization pace. The findings show that Romanian accountants are attracted by digitalization and feel comfortable with this change. Although the results show that the work experience is a factor that influences digitalization changes, there was not enough statistical evidence to confirm the findings. This study contributes to accounting digitalization literature by showing how accounting practitioners react to digitalization change and how the pace of digitalization is driven by their behavior and their experience.
\end{abstract}

Keywords: accounting practitioner, digitalization, RPA, experience, experiment.

\section{Introduction}

In the last few years, the progress in technology made significant changes in traditional accounting paradigm. Accountants around the world are facing an alert pace of digitalization and automatization, which could threaten their jobs because they are centralized in mundane tasks such as bookkeeping and data entry (Dimitriu \& Matei, 2014). Robotics process automation (RPA) is one of the new trends in accounting technology that could easily replace people for repetitive and routine tasks (Deloitte, 2017a). Large accounting companies have already started to adopt this technology to increase the efficiency and effectiveness (Cooper et al., 2019).

Although many authors study RPA and seek to identify how companies implement it and how they react to these changes (Deloitte, 2017a; Cooper et al., 2019; Kokina \& Blanchette, 2019; Lacurezeanu et al., 2020), only few studies analyze how people involved in the accounting profession react to this digitalization change (Deloitte, 2017b) and whether they are willing to embrace it. Moreover, as past behaviors have a significant influence on continued usage (Cheung \& Limayem, 2005) it is important to see how accountants react to digitalization changes depending on their work experience. Drawing on theory of reasoned action and the theory of changing management and using a case-based experiment with $2 \times 2$ between subjects and full factorial design, this study seeks to answer the following two research questions: How does the accountant behavior drive the pace of digitalization in the accounting field? To what extent the work experience of an accountant drives the pace of digitalization in the accounting field? Experimental method is barely used in accounting especially in Romania. The analysis is objective, leaves no room for interpretation and the reason of using it is related to the determination of causality. 
Our findings indicate that accountants are more attracted by automatization and feel more comfortable with it in comparison with manually working which means that they are open to digitalization changes and they are willing to embrace it. Although, the findings show that less experienced accountants are more attracted by automatization and feel more comfortable with it in comparison with high experienced accountants, we did not find enough statistical evidence to confirm this result. These findings contribute to digitalization in accounting literature by showing that the alert pace of digitalization is not only driven by management or companies that create digitalization, but also by people that should work with the new technologies.

The reminder of this paper is structured as follows. The next section provides some backgrounds about the digitalization impact on accounting profession and describes the use of RPA in accounting. Also, it describes the theories and develops the hypotheses. The following section explains the experimental design. We then present the results of our analysis and in the final section the main conclusions and limitations as well as directions for future research are given.

\section{Literature review \\ Backgrounds}

Digitalization is known as the third phase of technological advancement that involves significant changes in ways of business, working and role at many levels such as process, organization, business domain and society (Parviainen et al., 2017). Accounting field is one of the most affected by digital transformation given that most of the tasks performed by accountants are routine ones. As Knudsen (2020) states in his review, digitalization has the potential to influence accounting practices through many ways by bringing them into non-accounting functions. For example, Krahel and Tiera (2015) quoted by McKinney Jr et al. (2017) consider that accountants will do more analyses than data analysts due to Big Data. In addition, Moll and Yigitbasioglu (2019) believe that one task that could be performed by accountants is selecting relevant data and managing it to train artificial intelligence applications through validating, maintaining and ethically considering the quality of this data. Also, when it comes to robotic process automation (RPA), Kokina and Blanchette (2019) claims that there is a lot of incertitude with regards to roles that accountants would play. All these findings show that the accounting profession is likely to change due to digitalization in the following years.

RPA represents the use of software bots for automating highly repetitive, routine tasks that are normally performed by people, enabling faster handling time, reduced errors and costs and higher volumes (Deloitte, 2017). In line with this definition, Kokina and Blanchette (2019) found in their analysis of task characteristics that labor intensive, high volume, repetitive, in digital form, rule-based tasks using structured data and multiple systems are suitable for automation with RPA. Having that many areas in accounting imply such tasks, the potential of using RPA in this field is huge. Lacurezeanu et al. (2020) in their literature review about RPA in auditing and accounting highlights a series of tasks that are suitable for RPA implementation. The easiest to automate through RPA are the acquisition of inventories and services and their payments, end of period closings and monthly reporting. Another series of tasks could be accounts payable and accounts receivable management, customers, suppliers, debtors, creditors, invoices issuing/receiving, processing databases updates, approving, validating and making payments due or issuing payment notices etc. As an example of RPA implementation, the authors of the present paper give the case of a Finnish company from a study conducted by Gotthardt et al. (2020). The company presented in the case uses RPA to automate the bookkeeping of the accounts payable invoices that count around 2000 per month. The robot downloads the invoices received by e-mail, reads the PDF file, 
extracts data, converts data if necessary, login to accounting system and then makes the bookkeeping in the accounting system. All the above shows that people can be easily replaced by robots in the accounting domain for tasks that do not imply significant judgement. However, no one of these studies investigates how accountants react to these changes and whether the path of digitalization is driven by their behavior and their experience.

\section{Theory and hypotheses development}

PICBE |

770

According to ACCA (2020) study, there are three main components of digital transformation. The first one is technology that only has the role of the enabler even though it is a significant part of it. The second one is given by demographic sector targeted by the company which shows how the technology is used or consumed through its technologically literacy, changes in age profiles and birth rates within it or the level of acceptance. The third component is the societal value. The present paper focuses on the two first components in order to see how the digital transformation in the accounting field is driven by people demographics, in this case their work experience.

The behaviors and mindset of many accountants are conditioned and shaped by many factors such as academic studies, workplace colleagues, established business practices and legacy systems. A well-known theory that describes the technology acceptance by people is the theory of reasoned action which was developed by Fishbein and Ajzen (1975). In conformity with this theory, an intention for engaging in a certain behavior predicts the best whether a person engages in that behavior, whereas intentions are predicted by subjective norms and attitudes. In short, the more positively a certain action or behavior is considered by a person and the more important the behavior is for him and his family, friends and society, the more likely this person is to form intentions for engaging in that behavior and vice versa. In the case of the present study, if change in technology is positively perceived by a person, then the respective person will be more attracted by it and will feel more comfortable with it, and if change in technology is negatively perceived by a person, then that person will be less attracted by it and will feel less comfortable with it.

The theory of reasoned action has been utilized by many researchers for human behavior investigation in different areas of social psychology and also in technology acceptance studies. As an example, Mishra et al. (2014), have tested this theory to investigate the human behavior for the adoption of Green Information Technology. The findings of this study show that the actual behavior is positively influenced by the behavioral intention. Other studies have investigated whether the theory of reasoned action is suitable for testing the technology acceptance in comparison with other theories (Momani et al., 2017; Momani \& Jamous, 2017). The authors of these studies state that it is still needed to develop the technology acceptance theories.

On the other hand, people acceptance of change could be described by changing management theory. According to Burdus (2000), there are several reasons that cause resistance to change. The first one is selective attention and memory which states that the people perception on proposed change in organization depends on their worldview. In this case, people only partially take over the information change, filtering out the elements that force them to leave their comfort zone, thus obtaining an incomplete picture of the whole change process. In the case of the present study, depending on what people filter out from the process, they would be more willing or less willing to accept technological changes. The second one is related to the employee habits which shows that organizational changes that require employees' habits changes will be met with resistance, because any change in personal habits requires effort and therefore the exit from the personal comfort zone. Habits in general are not very easy to change. The more a person is used with a certain procedure, the less likely is for that person to change it. Habit confines the predictive 
power of intention on usage behavior because past behaviors have a significant influence on continued usage (Cheung \& Limayem, 2005). If this is the case, it can be predicted that employees which are used with a way of working for a long time will be less attracted by changes and more attracted by the old procedures and will feel more comfortable with these ones. The third cause in changing management theory is addiction to other people's opinion. In this research this could not be considered a cause because people should answer the questions individually, and they do not influence each other responses. Other three reasons that causes the resistance to change are fear of the unknown, economic reasoning and lack of security.

Having the above arguments, the three hypotheses of this paper are stated as follows:

$\mathrm{H} 1$ : Accounting practitioners are more attracted by automatization and feel more comfortable with it in comparison with manually working.

H2: Less experienced accountants are more attracted by automatization and feel more comfortable with it in comparison with manually working.

H3: There is an interaction effect such that the level of attractiveness and comfortability is stronger for automatization in the case of less experienced accountants.

\section{Methodology}

\section{Design}

This study uses a case-based experiment as a research method with $2 \times 2$ between subjects and a full factorial design which is presented in the Figure 1 below. Experimental methods have been used in technology related studies, especially to identify how people solve a problem by using different tools (Kerr \& Murthy, 2009; Tadesse \& Murthy, 2018). Participants of the study have been randomly assigned to one experimental group. The manipulated variable was automatization of the bookkeeping process that has been operationalized through its presence or absence in the two cases.

\begin{tabular}{|c|c|c|c|}
\hline \multicolumn{2}{|c|}{$\begin{array}{c}\mathbf{2 x 2} \\
\text { Design }\end{array}$} & \multicolumn{2}{c|}{ Accountant's experience } \\
\cline { 3 - 4 } & Yes & $\begin{array}{c}\text { Low experience } \\
\text { and automatization }\end{array}$ & $\begin{array}{c}\text { High experience } \\
\text { and automatization }\end{array}$ \\
\cline { 2 - 4 } Automatization & No & $\begin{array}{c}\text { Low experience } \\
\text { and no automatization }\end{array}$ & $\begin{array}{c}\text { High experience } \\
\text { and no automatization }\end{array}$ \\
\cline { 2 - 4 } & &
\end{tabular}

Figure 1. Factorial design

Source: Authors' own research.

In achieving the purpose of the present study, two hypothetical cases have been created related to management decision of RPA implementation for bookkeeping automatization in a Romanian company. In the first case-scenario, the decision was to automate the process and in the second one the decision was to not automate the process.

The independent variables used in this study are the automatization of bookkeeping which is measured through its presence or absence in the case-studies and the second independent variable is given by the work experience of the practitioner. The main idea is to see whether the accountant practitioner is more attracted by a company that implements RPA for bookkeeping automatization, in comparison with a company that do not implement it, depending on their work experience in the accounting field and whether the accounting practitioner feels comfortable with this change. The expected results are shown in the Figure 2 below. 


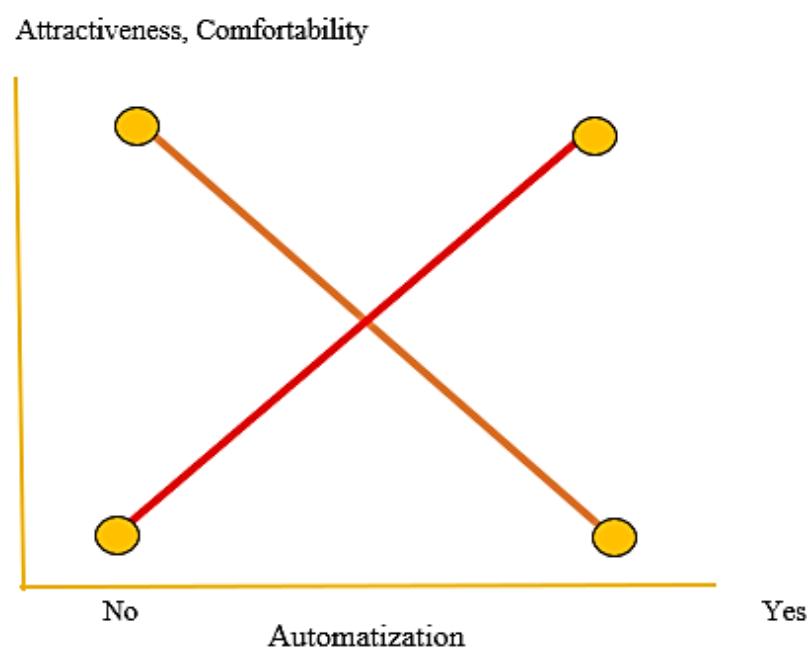

Figure 2. Expected results
PICBE |

772

\section{Participants}

Participants of this study are Romanian accounting practitioners. The reason we chose Romania is because this country ranks lower in the European Commission's Digital Economy ranking according to European Commission (2020) and we would like to see whether this situation is generally valid at the particular level of professional accountants. The data was collected during January 2021. For choosing the participants, we have first searched for a top accounting companies in Romania (either Romanian or multinational). After finding a good top, we have sent an e-mail to the owner of the site named Top Firme to ask for the permission of using it. Few days later, the permission has been given and a selection of top ten companies by turnover has been made. Subsequently, we were looking for a contact person in each company and sent them e-mails with the participation link. The contact person has been asked to share the link with the employees in the accounting department. After one week the number of observations reached to 22 and a reminder has been sent for each contact person. Following the reminder e-mail, we obtained a total of 56 observations in two weeks. In order to gain more observations, we increased the number of companies by choosing the next 10 companies from the top and we followed the same procedure. The top 20 companies are presented in Appendix 2. After other two weeks the total number of observations reached to 118. From the total sample, we removed 36 observations due to partial completion, resulting in a final sample of 82 observations that have been used for further analyses.

The population distribution on different demographics is shown in Table 1 below. From the total number of 82 observations, $80.5 \%$ were female participants and $19.5 \%$ were male participants. This is not surprisingly having that in Romania the accounting profession is mostly performed by women (Istrate, 2012) comparing with more developed European countries where accounting is known as a male profession. Most of the participants were between 25 and 30 years old (40.2\%) and on the opposite side were the participants that were over 45 years old (4.9\%). 60 participants (73.2\%) have finished their Master studies, 22\% Bachelor studies and only $4.9 \% \mathrm{PhD}$ studies. Moreover, $59.8 \%$ of the participants were working in a multinational company at the date of the study and the remaining $40.2 \%$ of the participants were working in a Romanian company. Also, with regards to professional certification, only $31.7 \%$ owe one, and the remaining part of $56 \%$ do not owe any professional accounting certification. 
Table 1. Population distribution by demographics

\begin{tabular}{|c|c|c|c|c|c|c|c|c|c|c|c|c|c|}
\hline \multicolumn{3}{|c|}{ Gender } & \multicolumn{3}{|c|}{ Age } & \multicolumn{3}{|c|}{ Level of studies } & \multicolumn{3}{|c|}{ Company type } & \multicolumn{2}{|c|}{$\begin{array}{l}\text { Professional } \\
\text { certification }\end{array}$} \\
\hline & $\mathbf{n}$ & $\%$ & & $\mathbf{n}$ & $\%$ & & $\mathbf{n}$ & $\%$ & & $\mathbf{n}$ & $\%$ & $\mathbf{n}$ & $\%$ \\
\hline Female & 66 & 80.5 & $<25$ & 16 & 19.5 & Bachelor & 18 & 22.0 & Multinational & 49 & 59.8 & Y 26 & 31.7 \\
\hline Male & 16 & 19.5 & $\begin{array}{l}>45 \\
25-30 \\
30-35 \\
35-40 \\
40-45\end{array}$ & $\begin{array}{l}4 \\
33 \\
12 \\
6 \\
11\end{array}$ & $\begin{array}{l}4.9 \\
40.2 \\
14.6 \\
7.3 \\
13.4\end{array}$ & $\begin{array}{l}\text { Master } \\
\text { PhD }\end{array}$ & $\begin{array}{l}60 \\
4\end{array}$ & $\begin{array}{l}73.2 \\
4,9\end{array}$ & Romanian & 33 & 40.2 & N 56 & 68.3 \\
\hline$\sum$ & 82 & 100 & $\sum$ & 82 & 100 & $\sum$ & 82 & 100 & $\sum$ & 82 & 100 & $\sum 82$ & 100 \\
\hline
\end{tabular}

PICBE |

\section{Tasks}

As previously discussed, the research method is an experiment that measures to what extend the work experience of an accountant drives the digitalization pace and whether there is a difference in the level of attraction and comfortability between manually working and automatization. The experiment has been administrated online by using Qualtrics with two different blocks which have been randomized with an equal number of participants for each case. The average time of completing the experiment was approximatively 3.15 minutes without considering the outliers. The reason of excluding the outliers is related to the application that gives you the opportunity to leave the session and continue anytime from the point that the session has been left.

The experiment consists in three parts. First, participants have been asked to fill in the demographic questions (gender, age, work experience, level of studies, whether they owe any professional certifications, the company type that they work for-Romanian or multinational). The question about experience was one of the most important having that the study seeks to find whether this is a factor that influences the pace of digitalization in the accounting field. In order to split the groups in respondents with less experience and respondents with more experience, we have first calculated the median of the work experience in years and assigned the participants with work experience below median in one group and those above the median in the other group. The work experience median in years was 5 . The reason of taking the median into consideration and not taking the average age was related groups inequality.

The second part of the experiment consisted in a hypothetical case about a company named Alpha, which is an accounting Romanian company that decides (in de first case) or not decides (in the second case) to automate the bookkeeping process by using RPA. Participants assigned in the first condition had to read the first case and those assigned in the second condition had to read the second case. Based on the case-scenarios, respondents had then to answer two questions on a 5points Likert scale. In the first question, participants were asked how attracted are by company Alpha assuming that they are taking into consideration a position in that company and in the second question, participants were asked how comfortable they feel with the management decision of bookkeeping automatization assuming that they already work in that company. The two questions have been the same in both case-scenarios.

The third part of the study consisted in manipulation checks to see whether participants understood the case. In both case-scenarios respondents had to answer with "yes" or "no" on whether the management's decision was to automate the bookkeeping process by using RPA. 


\section{Results and discussions}

\section{Descriptive statistics and hypotheses testing}

Table 2. Descriptive statistics

\begin{tabular}{|c|c|c|c|c|c|}
\hline \multicolumn{6}{|c|}{ Panel A. Dependent Variable: Attractiveness (mean [SD]) } \\
\hline Automatization & $\mathbf{n}$ & High experienced & $\mathbf{n}$ & Less experienced & $\sum$ \\
\hline No & 22 & $3.14(1.04)$ & 23 & $2.87(0.97)$ & $3.00(1.00)$ \\
\hline Yes & 15 & $3.80(1.27)$ & 22 & 3.77 (1.07) & $3.78(1.13)$ \\
\hline$\sum$ & 37 & $3.41(1.17)$ & 45 & $3.31(1.10)$ & $3.35(1.13)$ \\
\hline \multicolumn{6}{|c|}{ Panel B. Dependent Variable: Comfortability (mean [SD]) } \\
\hline Automatization & $\mathbf{n}$ & High experienced & $\mathbf{n}$ & Less experienced & $\sum$ \\
\hline No & 22 & $3.05(1.05)$ & 23 & $2.91(0.90)$ & $2.98(0.97)$ \\
\hline Yes & 15 & $3.93(1.98)$ & 22 & $3.91(1.02)$ & $3.92(1.12)$ \\
\hline$\sum$ & 37 & $3.41(1.21)$ & 45 & $3.40(1.07)$ & $3.40(1.13)$ \\
\hline
\end{tabular}

Source: Authors' own research.

As we can see in the Table 2, participants are more attracted by automatization (mean = 3.78 ) than manually working (mean $=3.00$ ). Moreover, participants with high experience in the accounting field are on average more attracted by a company that does not automate the process of bookkeeping $($ mean $=3.14)$ than less experienced participants (mean $=2.87$ ), but also more attracted by a company that automate this process (mean $=3.80)$ than participants with lower experience (mean $=3.77$ ). The results could also be seen in the Figure 3 below, which shows that the expected effects are only met for the difference between automatization factor and not met for the experience factor. Therefore, further analyses are not needed for the second factor and for the interaction effect.

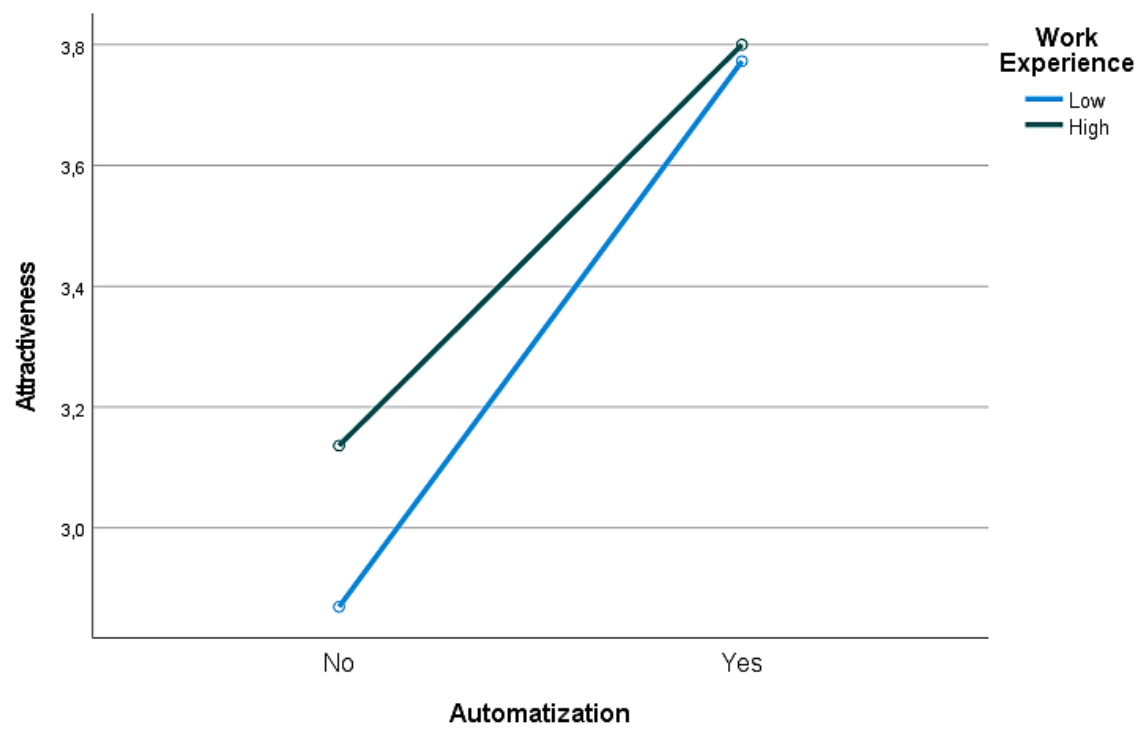

Figure 3. Results (attractiveness)

Source: Authors' own research. 
When it comes to comfortability the situation looks similar. Accountants feel more comfortable with automatization (mean $=3.92$ ) comparing with manually working (mean $=2.98$ ). Also, high experienced accountants feel on average more comfortable if the management decides not to automate the process $($ mean $=3.05)$ than less experienced accountants $($ mean $=2.91)$. They also feel more comfortable when the management decides to automate the process $($ mean $=3.93$ ) than less experienced accountants (mean =3.91). Figure 4 shows the results for comfortability. As well as in the case of attractiveness as dependent variable, further analyses are not necessary for the factor experience and for the interaction effect for testing the second and the third hypotheses.

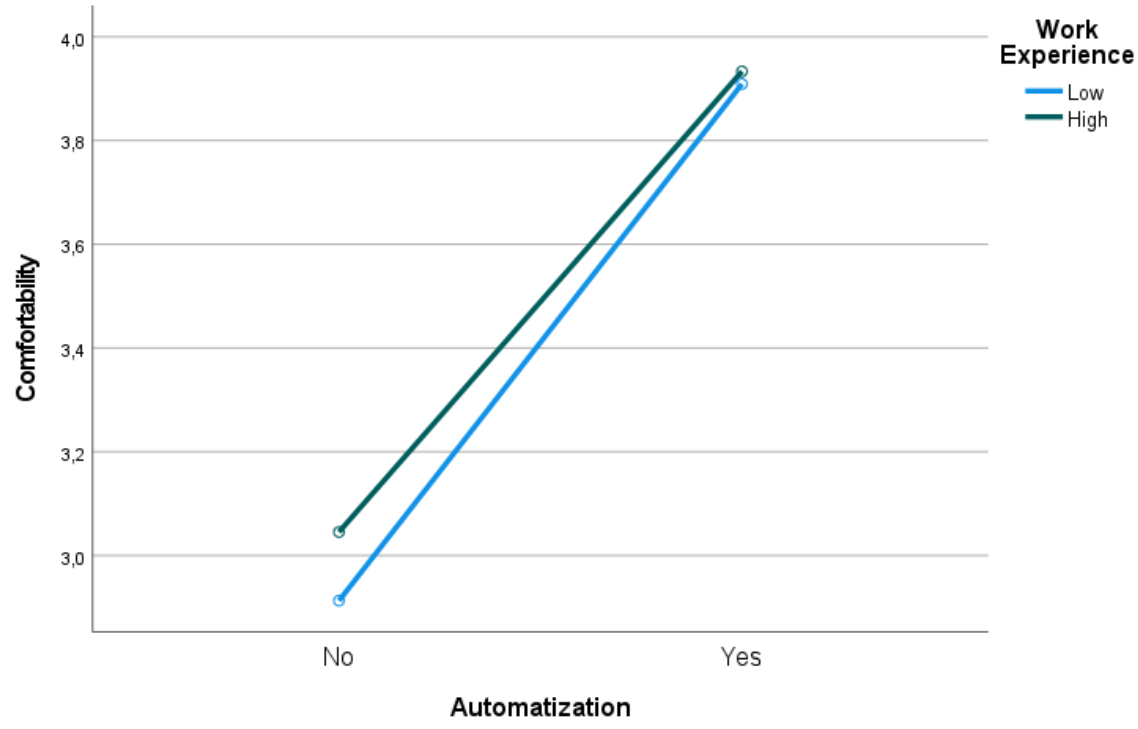

Figure 4: Results (Comfortability)

Source: Authors' own research.

As previously discussed, the second and the third hypotheses will not be tested having that preliminary analyses are not similar with the expected ones. As such, only the first hypothesis will be tested using an independent sample T-test to check whether there is a significant difference between the two groups that received the different cases related to automatization. The hypothesis one tests results are shown in Table 3 below.

Table 3. Hypothesis 1 testing

\begin{tabular}{|lrrrrr|}
\hline & t & df & p-value & Mean Difference & Std. Error Difference \\
& & & & & \\
\hline Attractiveness & $-3,284$ & 72,513 &, 002 &,- 784 &, 239 \\
Comfortability & $-4,039$ & 71,737 &, 000 &,- 941 &, 233 \\
\hline
\end{tabular}

As we can see, the mean difference for the dependent variable "attractiveness" between the group that received the case of no automatization and the group that received the case of automatization is -0.784 and the result is significant at a level of $1 \%$ (p-value $<0.01$ ) providing statistical support for the first hypothesis. For the dependent variable "comfortability" this difference is equal with -0.941 and the result is also significant (p-value $<0.01$ ). Therefore, the hypothesis 1 is also supported in case of comfortability as dependent variable. 


\section{Manipulation checks tests and analyses}

The manipulated variable in this study is automatization of bookkeeping process. As discussed in the previous section, participants had to answer a question on whether the management's decision was to automate the bookkeeping process by using RPA. This question let us see whether participants understood the case and whether they based their answers on it. Following this verification, 19 observations have been removed, resulting in a sample of 63 observations that have been used in performing new analyses. The descriptive statistics are displayed in the Table 4 below.

Table 4. Descriptive statistics without manipulation checks failures

\begin{tabular}{|lcllll|}
\hline \multicolumn{6}{|l|}{ Panel A. Dependent Variable: Attractiveness (mean [SD]) } \\
\hline Automatization & $\mathbf{n}$ & High experienced & n & Less experienced & $\sum$ \\
\hline No & 16 & $2.94(1.00)$ & 15 & $2.47(0.83)$ & $2.71(0.94)$ \\
Yes & 14 & $3.86(1.29)$ & 18 & $3.89(0.90)$ & $3.88(1.07)$ \\
$\sum$ & 30 & $3.37(1.21)$ & 33 & $3.24(1.12)$ & $3.30(1.16)$ \\
\hline \multicolumn{7}{l}{ Panel B. Dependent } & Variable: Comfortability (mean [SD]) & & \\
\hline Automatization & $\mathbf{n}$ & High experienced & $\mathbf{n}$ & Less experienced & $\sum$ \\
\hline No & 16 & $2.94(1.00)$ & 15 & $2.60(0.74)$ & $2.77(0.88)$ \\
Yes & 14 & $3.86(1.29)$ & 18 & $4.00(0.97)$ & $3.94(1.11)$ \\
$\sum$ & 30 & $3.37(1.22)$ & 33 & $3.36(1.11)$ & $3.37(1.15)$ \\
\hline
\end{tabular}

Source: Authors' own research.

As we can see in the Table 4, participants are more attracted by automatization (mean = 3.88 ) than manually working (mean $=2.71$ ). Moreover, participants with high experience in the accounting field are on average more attracted by a company that does not automate the process of bookkeeping (mean $=2.94$ ) than less experienced participants (mean $=2.47$ ), and less attracted by a company that automate this process (mean $=3.86$ ) than participants with less experience (mean $=3.89$ ). The results can also be seen in the Figure 5 below that shows a small interaction effect between the two independent variables.

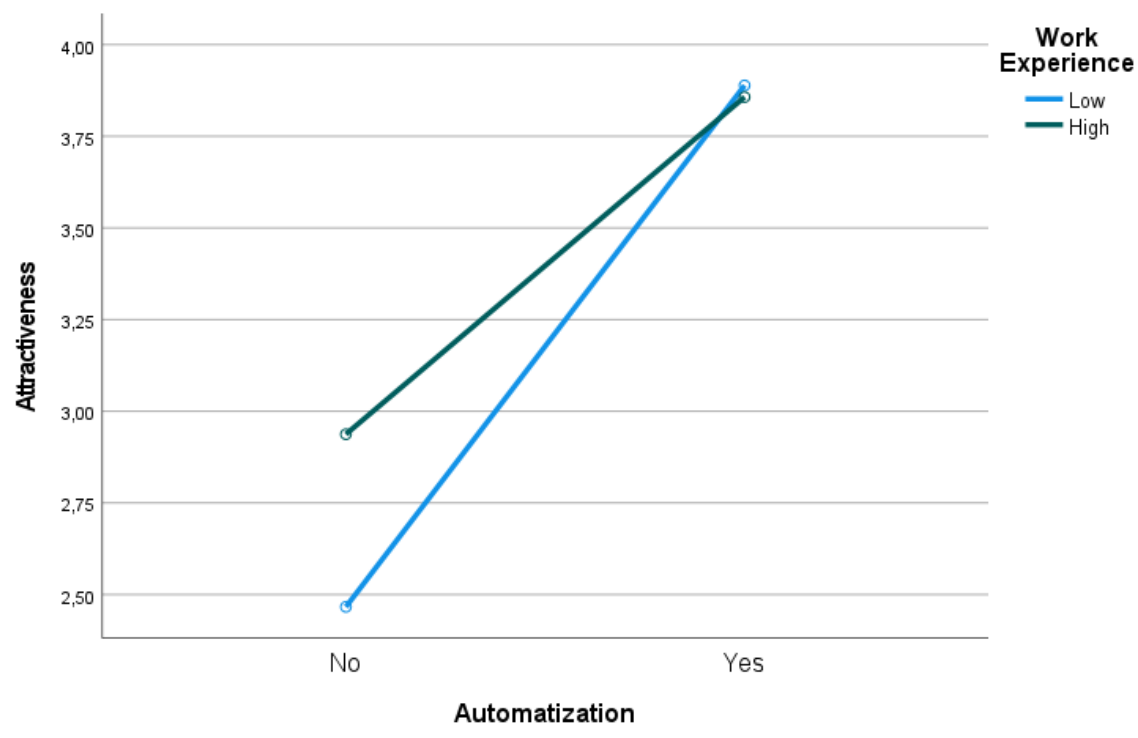

Figure 4. Results (Attractiveness without manipulation checks failures)

Source: Authors' own research.

DOI: 10.2478/picbe-2021-0072, pp. 768-782, ISSN 2558-9652|

Proceedings of the $15^{\text {th }}$ International Conference on Business Excellence 2021 
In terms of comfortability the situation looks similar. Accountants feel more comfortable with automatization (mean $=3.94$ ) comparing with manually working (mean $=2.77$ ). Also, high experienced accountants feel on average more comfortable if the management decides not to automate the process (mean $=2.94)$ than less experienced accountants (mean $=2.60)$ and less comfortable when the management decides to automate the process (mean $=3.96$ ) than less experienced accountants (mean $=4.00$ ). Figure 5 displays the results for comfortability after eliminating the manipulation checks failures and shows an interaction effect between automatization and work experience.

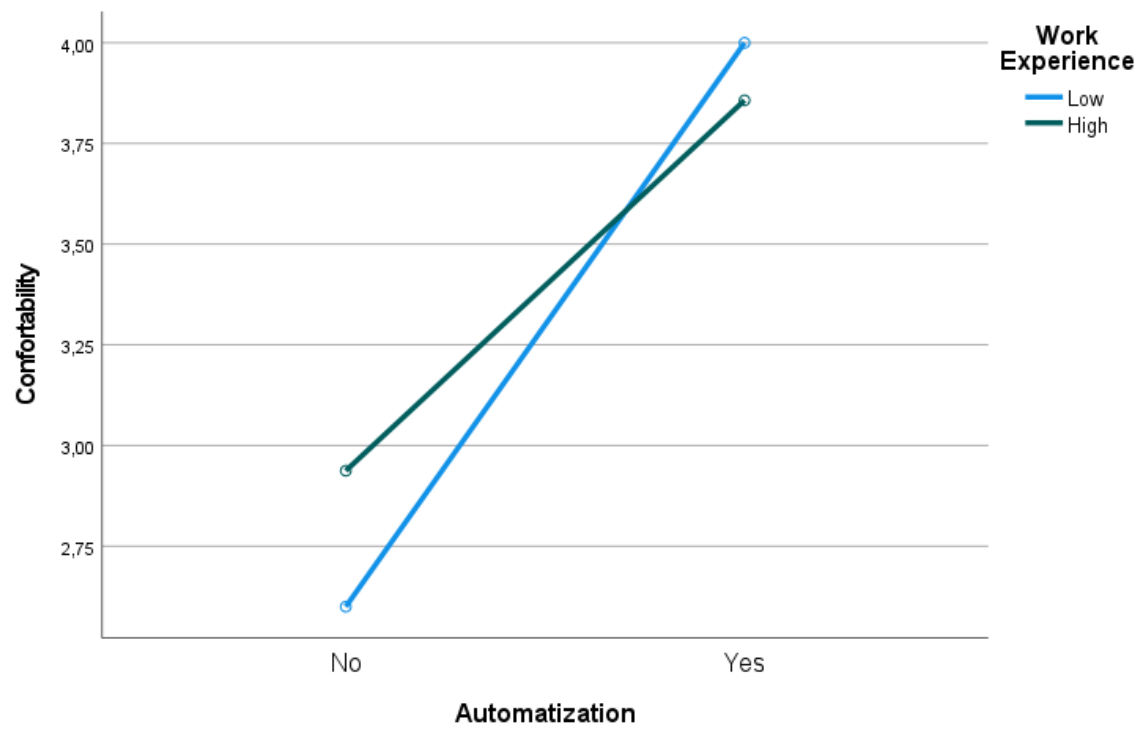

Figure 5. Results (Comfortability without manipulation checks failures)

Source: Authors' own research.

Table 5. Hypotheses testing

Panel A. Results of ANOVA on dependent variable Attractiveness

\begin{tabular}{|c|c|c|c|c|c|}
\hline Source & Sum of Squares & df & Mean Square & $\mathbf{F}$ & p-value \\
\hline Corrected Model & 23,107 & 3 & 7,702 & 7,553 &, 000 \\
\hline Automatization & 21,411 & 1 & 21,411 & 20,997 &, 000 \\
\hline Experience &, 753 & 1 &, 753 & ,738 & ,394 \\
\hline Automatization * Experience & ,986 & 1 & ,986 & ,967 &, 329 \\
\hline Error & 60,163 & 59 & 1,020 & & \\
\hline \multicolumn{6}{|c|}{ Panel B. Results of ANOVA on dependent variable Comfortability } \\
\hline Source & Sum of Squares & df & Mean Square & $\mathbf{F}$ & p-value \\
\hline Corrected Model & 22,351 & 3 & 7,450 & 7,296 &, 000 \\
\hline Automatization & 21,006 & 1 & 21,006 & 20,570 &, 000 \\
\hline Experience &, 148 & 1 & ,148 &, 145 & ,705 \\
\hline Automatization * Experience & ,901 & 1 & ,901 & ,882 & ,351 \\
\hline Error & 60,252 & 59 & 1,021 & & \\
\hline
\end{tabular}

The ANOVA results indicate that the effect of bookkeeping automatization on participants' attractiveness (Table 5, Panel A) and participants' comfortability (Table 5, Panel B) was statistically significant ( $p$-value $<0.01$ ) and provides evidence for the first hypothesis which states that accounting practitioners are more attracted by automatization and feel more comfortable 
with it in comparison with manually working. As well as specialists are expecting (Deloitte 2017b, ACCA, 2020), accounting practitioners understood the need of digitalization and the threaten that it gives to them and they are willing to embrace it.

Furthermore, the effect of experience was not statistically significant neither on attractiveness $(p$-value $=0.394)$ nor on comfortability $(p$-value $=0.705)$ and therefore the second hypothesis needs to be rejected. Although past behaviors have a significant influence on continued usage (Cheung \& Limayem, 2005), this is not necessary the case for high experienced accounting practitioners that took part of our experiment. Also, the interaction effect between automatization and work experience on attractiveness and comfortability was not statistically significant (p-value $=0.329 ; 0.351)$ and cannot provide support for the third hypothesis.

\section{Conclusions}

This paper has investigated accounting practitioners' reaction to digitalization changes and more specifically to the automatization of the routine tasks such as bookkeeping by using RPA. Also, it has investigated whether the work experience of an accountant is a factor that drives the pace of digitalization in the accounting field. Using a case-based experiment with $2 \times 2$ between subjects and full factorial design, the findings show that Romanian accountants are more attracted by automatization and feel more comfortable with it in comparison with manually working. As the theory of reasoned action states (Fishbein \& Ajzen (1975), this result indicates that changing in technology is positively perceived by accountants and they are likely to form intentions to engage in this change. Also, as specialists are expecting, people understand the need of digitalization and they are willing to embrace it and we expect companies to grow and have a higher yield due to this.

With regards to work experience, even though less experienced accountants are more attracted by automatization and feel more comfortable with it in comparison with high experienced accountants, there was not enough statistical evidence to confirm these findings. This result is not surprising having that most of the participants are young. This generation of accountants are part of the millennial generation (White et al. (2020) and one of their defining characteristics is the affinity with the digital world (PwC, 2020). Also, participants work in top accounting companies that usually recruit young people that are open to changes. Moreover, top companies seek to reduce the manually working and people have already gotten used to automatization, which is a limitation of this study. As a direction for future research, this paper aims to invite more older participants and participants that work in small companies that do not have such a big potential to invest in automatization as big companies.

The results of this study could be of interest for accounting companies to see how people react to digitalization changes and whether they are ready to embrace them. Also, the results could be of interest for scholars and professional accounting institutions.

\section{References}

ACCA (2020). The digital accountant: Digitalization skills in a transformed world. Retrieved from https://www.accaglobal.com/ie/en/professional-insights/technology/The_Digital_Ac countant.html.

Burdus, E., Caprarescu, G., \& Androniceanu, A. (2000). Managementul schimbării organizaţionale. Editura Economică, Bucharest, Romania, 632. 
Cheung, C., \& Limayem, M. (2005). The Role of Habit in Information Systems Continuance: Examining the Evolving Relationship Between Intention and Usage. ICIS 2005, Proceedings. 39, https://aisel.aisnet.org/icis2005/39.

Cooper, L.A., Holderness, Jr., D.K., Sorensen, T.L., \& Wood, D.A. (2019). Robotic Process Automation in Public Accounting, Accounting Horizons. 33 (4), 15-35.

Deloitte (2017a). Automation is here to stay... but what about your workforce? Preparing your organization for the new worker ecosystem, Retrieved from https://www2deloitte.com/ content/dam/Deloitte/global/Documents/FinancialServices/gx-fsiautomation-here-to-stay .pdf.

Deloitte (2017b). The robots are ready. Are you? Untapped advantage in your digital workforce, Retrieved from https:/www2.deloitte.com/content/dam/Deloitte/bg/Documents/techno logy-media-telecommunications/Deloitte-us-cons-global-rpa-survey.pdf.

Dimitriu, O., \& Matei, M. (2014). A new paradigm for accounting through cloud computing, Procedia Economics and Finance, 15, 840-846.

EU Commission (2020). The Digital Economy and Society Index (DESI), Retrieved from https://ec.europa.eu/digital-single-market/en/digital-economy-and-society-index-desi.

Fishbein, M., \& Ajzen, I. (1975). Belief, Attitude, Intention, and Behavior: An Introduction to Theory and Research. Reading. MA, Addison-Wesley.

Gotthardt, M., Koivulaakso, D., Paksoy, O., Saramo, C., Martikainen, M., \& Lehner, O. (2020). Current state and challenges in the implementation of smart robotic process automation in accounting and auditing, ACRN Journal of Finance and Risk Perspectives.

Istrate, C. (2012). Gender issues in Romanian accounting profession, Review of Economics and Business Studies, 5(2), 21-45.

Kerr, D.S., \& Murthy, U.S. (2009). Beyond brainstorming: The effectiveness of computermediated communication for convergence and negotiation tasks, International Journal of Accounting Information Systems, 4(10): 245-262.

Knudsen D.R. (2020). Elusive boundaries, power relations, and knowledge production: a systematic review of the literature on digitalization in accounting, International Journal of Accounting Information Systems, (36), 100441.

Kokina, J., \& Blanchette, S. (2019). Early evidence of digital labor in accounting: Innovation with Robotic Process Automation, International Journal of Accounting Information Systems. (35), 100431.

Lacurezeanu, R., Tiron-Tudor, A., \& Bresfelean, V.P. (2020), Robotic Process Automation in Audit and Accounting, Audit Financiar, 4(160), 752-770.

McKinney, Jr.E., Yoos, II, C.J., \& Snead, K., (2017). The need for 'skeptical' accountants in the era of Big Data, Journal of Accounting Education. 38, 63-80.

Mishra, D., Akman, I., \& Mishra, A. (2014). Theory of Reasoned Action application for Green Information Technology acceptance, Computers in Human Behavior, 36, 29-40.

Moll, J., \& Yigitbasioglu, O. (2019). The role of internet-related technologies in shaping the work of accountants: New directions for accounting research, The British Accounting Review, 51, 10833.

Momani, A.M., \& Jamous, M.M. (2017). The Evolution of Technology Acceptance Theories, International Journal of Contemporary Computer Research, 1(1).

Momani, A.M., Hilles, S.M., \& Jamous, M. (2017). Technology acceptance theories: Review and Classifications, International Journal of Cyber Behavior, 7(2), 1-14. 
Parviainen, P., Tihinen, M., Kääriäinen, J., \& Teppola, S. (2017). Tackling the digitalization challenge: how to benefit from digitalization in practice, International Journal of Information Systems and Project Management 5 (1), 63-77.

PricewaterhouseCoopers (2020). Millennials at work. Reshaping the workplace. Retrieved from https://www.pwc.com/co/es/publicaciones/assets/millennials-at-work.pdf.

Tadesse, A.F., \& Murthy, U.S. (2018). Nonprofessional investor perceptions of the partial remediation of IT and non-IT control weaknesses: An experimental investigation, International Journal of Accounting Information Systems, (28), 14-30.

White, B.S., Davidson, B.I., \& Cullen, Z. (2020). Career Anchors of Millennial Accountants, Advances in Accounting Behavioral Research, (33).

\section{Appendices}

\section{Pre-phase: Welcome}

\section{Appendix 1 - Case experiment scenarios}

Welcome to this study! My name is Oana Cristina Stoica and I'm currently a PhD student at Bucharest, University of Economic Studies. This study is part of my $\mathrm{PhD}$ thesis and it relates to accounting digitalization.

Thank you for agreeing to take part of this study. This survey will only take few minutes to complete. Your answers are only used in this study and will be kept with the strictest confidentiality.

\section{Phase 1: Pre-experimental questions}

Before we start the case study, I would like to know some general information about you. Please give an answer for the questions below:

1. What is your gender?

Male/Female

2. What is your age?

Intervals - (under 25, 25-30, 30-35, 35-40, 40-45, over 45)

3 . What is your education level?

High School / Bachelor's degree / Master's degree / $\mathrm{PhD}$ degree

4. How many years now have you worked in the accounting field?

Please specify the number of years

5. Do you owe any accounting professional certification (CECCAR, CAFR, ACCA, others)? Yes/No

6. What type of company do you work for?

Romanian/Multinational

\section{Phase 2 - Actual experiment}

Please read the information below carefully to provide answers for the questions that will follow.

\section{Case 1 - automation}

Alpha is an accounting Romanian company founded in 2008 that provides professional services for a portfolio of more than 300 clients in different industries and sectors.

Alpha's employees are now bookkeeping the documents received from clients manually or by using excel importing files processed by them in a well-known Romanian accounting soft. After 
many calculations and budgeting, company's management have taken the decision to automate this process by hiring a company that provides robotic process automation (RPA) services. The management claims that the benefits of RPA are likely to overweight the cost of manually bookkeeping on long term and will make the accountants' work easier. Before this change will take place, the company ask the employees to engage in this project by helping the RPA providers to understand the accounting flow and supporting them whenever is necessary.

Assume you are considering a position in this company. On a scale of 1 to 5 ( 1 - not at all attractive, 5 - extremely attractive), how attractive is this company as an employer for you?

Assume you already work in this company. On a scale of 1 to 5 (1- not at all comfortable, 5 - extremely comfortable), how comfortable do you feel with the management's decision?

\section{Case 2 - keep manually}

Alpha is an accounting Romanian company founded in 2008 that provides professional services for a portfolio of more than 100 clients in different industries and sectors.

Alpha's employees are now bookkeeping the documents received from clients manually or by using excel importing files processed by them in a well-known Romanian accounting soft. Company's management have taken into consideration to automate this process by hiring a company that provides robotic process automation (RPA) services, but after many calculations and budgeting the decision was to keep the process as it is for at least two or three years more. The management claims that the benefits of RPA are not likely to overweight the cost of manually bookkeeping on long term. Because of that, company's employees will still work manually during the mentioned period.

Assume you are considering a position in this company. On a scale of 1 to 5 ( 1 - not at all attractive, 5 - extremely attractive), how attractive is this company as an employer for you?

Assume you already work in this company. On a scale of 1 to 5 (1-not at all comfortable, 5 - extremely comfortable), how comfortable do you feel with the management's decision?

\section{Phase 3 - Exit questionnaire}

- Manipulation checks

The management's decision was to automate the bookkeeping process by using RPA.

Yes / No

- Participants' experience

If you would like to give some suggestions/improvements with regards to the study, please leave them below.

\section{Phase 4 - Exit screen}

You have reached at the end of this study. Thank you very much for your involvement. If you are interested in study's results and you would like to receive them, please let me know.

Wish you the best of luck in your accounting journey, Oana 
Appendix 2 - Top companies

\begin{tabular}{|l|l|c|}
\hline \multicolumn{1}{|c|}{ Ref. no } & \multicolumn{1}{|c|}{ Company name } & Turnover (RON) \\
\hline 1 & ERNST AND YOUNG & $423,056,854.00$ \\
\hline 2 & PRICEWATERHOUSECOOPERS & $220,371,671.00$ \\
\hline 3 & KPMG & $186,165,374.00$ \\
\hline 4 & DELOITTE & $170,303,131.00$ \\
\hline 5 & BDO & $39,628,771.00$ \\
\hline 6 & MAZARS & $36,185,352.00$ \\
\hline 7 & TMF ROMANIA SRL & $26,435,913.00$ \\
\hline 8 & Fin Expert Consulting SRL & $17,908,128.00$ \\
\hline 9 & Vulpoi \& Toader Management SRL & $17,542,197.00$ \\
\hline 10 & TPA & $16,796,155.00$ \\
\hline 11 & ROEDL AND PARTNERS & $15,039,803.00$ \\
\hline 12 & SOTER SRL & $13,446,347.00$ \\
\hline 13 & CONTEXPERT CONSULTING SRL & $13,028,943.00$ \\
\hline 14 & BOSCOLO AND PARTNERS CONSULTING SRL & $12,914,281.00$ \\
\hline 15 & RSM ROMANIA & $11,341,698.00$ \\
\hline 16 & ACCACE OUTSOURCING & $10,627,346.00$ \\
\hline 17 & TAXHOUSE SRL & $9,209,271.00$ \\
\hline 18 & NESTOR NESTOR DICULESCU KINGSTON PETERSEN & $9,020,506.00$ \\
\hline 19 & CONSULTANTA FISCALA SRL & $8,642,981.00$ \\
\hline 20 & NOERR FINANCE AND TAX & $8,499,303.00$ \\
\hline
\end{tabular}

PICBE |

Source: authors' processing using https://www.topfirme.com/caen/6920/cifra-de-afaceri/.

DOI: 10.2478/picbe-2021-0072, pp. 768-782, ISSN 2558-9652 |

Proceedings of the $15^{\text {th }}$ International Conference on Business Excellence 2021 